\title{
Equipment
}

\section{A Prospective Clinical Comparison of Two Intravenous Polyurethane Cannulae\#}

\author{
W. J. RUSSELL*, S. MICIK†, S. GOURD $\neq, H$. MACKAY§, S. WRIGHT** \\ Departments of A naesthesia and Intensive Care, and Cardiothoracic Services, Royal Adelaide Hospital, Adelaide, S.A .
}

\section{SU M M A RY}

Tissue irritation, as evidenced by phlebitis, associated with O ptiva ${ }^{\mathrm{TM}}$ (Johnson \& Johnson M edical) and Insyte ${ }^{\mathrm{TM}}$ (Becton Dickinson) polyurethane cannulae was studied. The integrity of the cannulae on removal, the incidence of infection at the cannula site and the factors which influence phlebitis were also examined.

One thousand and eight patients had a polyurethane cannula placed for induction of anaesthesia for cardiac surgery. After surgery, the cannula was examined every 24 hours. If evidence of phlebitis occurred, the cannula was removed and sent for culture. All remaining cannulae were removed at 72 hours and the site examined daily for a further three days.

There were 5030 ptiva $^{T M}$ and 505 Insyte $^{T M}$ cannulae studied. The distributions between the two cannulae with respect to patient characteristics, gauge of cannula, number of attempts and difficulty of insertion, cannula site and anaesthetist inserting were similar. The early removal rate for both groups was $47 \%$.

O verall phlebitis rate with 0 ptiva ${ }^{T M}$ was $31 \%$ and Insyte ${ }^{T M} 33 \%$. This difference is not statistically significant. The cumulative phlebitis rate increased with time but did not differ between the two types of cannulae.

Minor tip distortion or shaft kinking of the cannulae occurred in $16.2 \%$ of 0 ptiva ${ }^{\mathrm{TM}}$ and $23.5 \%$ of Insyte ${ }^{\mathrm{TM}}$. This difference is statistically significant and may relate to the slightly more acute taper at the 0 ptiva $^{\mathrm{TM}}$ cannula tip. Both cannulae were similar in clinical performance.

Key Words: EQUIPMENT: polyurethane cannulae; ANAESTHETIC TECHNIQUES: intravenous cannulation; COM PLICATIONS: phlebitis

Phlebitis is a well-recognized complication of intravenous therapy. Several factors have been shown to contribute to phlebitis. Maki and R inger reported a risk of phlebitis over $50 \%$ after four days insertion ${ }^{1}$ and identified patient and other factors which contributed to the phlebitis rate. Female patients were found to be 1.9 times more likely to get phlebitis and insertion on the forearm was more likely to result in

\footnotetext{
\# Because of a printer's error in the D ecember 1996 issue of A naesthesia and Intensive Care (Vol. 24, No. 6, p. 708, Figure $4)$, this paper is reprinted here in its entirety and in its correct form

*F.R.C.A., F.A.N.Z.C.A., Ph.D., Director, Research and Development, D epartment of A naesthesia and Intensive Care.

†B.N.(Flinders), C.N., D epartment of Cardiothoracic Services. $\ddagger R$.N., Clinical N urse, D epartment of Cardiothoracic Services. $\S B . N$.(Flinders), Clinical N urse, D epartment of Cardiothoracic Services. **R .N., Clinical N urse, D epartment of Cardiothoracic Services.

Address for Reprints: D r W. J. Russell, D epartment of A naesthesia and Intensive Care, R oyal A delaide H ospital, N orth Terrace, S.A . 5000.

A ccepted for publication on A ugust 8, 1996.
}

phlebitis than insertion into the hand or wrist. They also reported that the catheter material affected the incidence of phlebitis. A cannula made from Teflon ${ }^{\mathrm{TM}}$ was 1.37 times more likely after a few days to cause phlebitis than one made with polyurethane $\left(\right.$ Vialon $\left.{ }^{\mathrm{TM}}\right)$. Larsson and colleagues suggested that this might be explained by chemical leeching from the different cannula materials ${ }^{2}$. A difference in phlebitis rates for the two materials was supported by a study by $\mathrm{M}$ CK ee et al in 191 patients. They found a phlebitis rate at 72 hours of $31 \%$ for $V$ ialon ${ }^{\mathrm{TM}}$ and a $51 \%$ rate for Teflon ${ }^{\text {TM } 3}$. A larger study of 645 cannulae used for induction of anaesthesia by $\mathrm{G}$ aukroger et al but which remained in for up to four days also found that Vialon $^{\text {TM }}$ had only $54 \%$ of the phlebitis risk of Teflon $^{\mathrm{TM} 4}$. H owever, a double-blind randomized controlled comparison of both types of cannulae at the Central Middlesex Hospital in L ondon failed to find any difference in phlebitis rate over five days ${ }^{5}$. 
The difference in findings is difficult to explain. One possible explanation is the difference in treatment of the Teflon ${ }^{\text {TM }}$ surface. A Il the positive studies were comparing the Insyte ${ }^{T M}$ made of Vialon ${ }^{T M}$ by Becton Dickinson with the $\mathrm{Jelco}^{\mathrm{TM}}$ made of Teflon ${ }^{\mathrm{TM}}$ by J ohnson \& J ohnson M edical. The negative study used a Teflon ${ }^{\text {TM }}$ Vasculon $^{\text {TM }}$ cannula made by ViggoSpectramed. The microscopic surface properties of similar material can be different. A study by Tebbs et al of polyurethane catheters showed that the smoothness of the surface differed substantially ${ }^{6}$ and the smoother surfaces were associated with a lower bacterial colonization after one hour of incubation. Thus even if cannulae are made of the same material, other factors may still create a significant difference in the clinical phlebitis rate. A lthough the new 0 ptiva $^{\text {TM }}$ cannula is made of polyurethane, the cannula is transparent and claimed by the company to be an improvement on the Vialon ${ }^{\mathrm{TM}}$ polyurethane. In addition, the inserting needle is of a different profile, being backsharpened and it is claimed that about a $20-30 \%$ smaller force is required for needle and cannula insertion. This could alter the tissue damage on insertion.

As the major concern for most clinicians is how long they can use an intravenous cannula, a trial was designed to prospectively compare the two clinically available polyurethane cannulae, 0 ptiva $^{\mathrm{Tm}}$ from Johnson \& Johnson Medical and Insyte ${ }^{\mathrm{TM}}$ from Becton Dickinson with particular reference to phlebitis, which is the most common limiting factor for long term use.

\section{METHODS}

Patients undergoing cardiac surgery were randomly allocated to have their induction through either an O ptiva ${ }^{T M}$ or Insyte ${ }^{T M}$ polyurethane cannula. R andomization was determined by a table of random numbers. A II patients were greater than 18 years old and gave informed consent as approved by the R oyal A delaide H ospital E thics Committee.

Patients were excluded if informed consent was not possible or the patient refused. They were also excluded if there was evidence of infection, or the cannulae were not suitable for the patient.

The chosen cannula was inserted by an experienced anaesthetist and then connected to an infusion set running a balanced electrolyte solution. This set was used for the induction of anaesthesia and the administration of drugs and fluids during the operation. A fter the patient was in the cardiac intensive care and stable so that this IV line was no longer required, the cannula was capped and flushed with heparin saline. This cannula then remained in for a total of three days, after which it was removed and the site observed daily for a further three days for evidence of phlebitis or infection. After capping, an injection through the cannula of heparin saline flushing solution ( 50 units in $5 \mathrm{ml}$ ) was ordered eight hourly prn.

Daily monitoring of the cannula site was performed by one of the three study nurses. The cannula site was assessed for any signs of phlebitis such as erythema, oedema, pain or tenderness, streak formation, a palpable venous cord or any exudate. If this occurred within the three days, the cannula was removed. If evidence of phlebitis occurred at any time during the six days observation, the site was swabbed and the swab sent for culture. In addition, the degree of phlebitis was graded as mild (pain and/or erythema), moderate (oedema and/or streaking along vein) or severe (a palpable venous cord and/or exudate at cannula site). If a patient had more than one symptom or sign, then the highest appropriate category was used. This scoring was done at the time the cannula was removed or during the subsequent post-decannulation observation and the maximum reaction scored.

Immediately after removal, the cannula was examined macroscopically and any damage or deformation recorded.

Demographic data was collected on the patients and a record was kept of all drugs administered during the three days the cannula was in. In addition, data about the insertion was also recorded. This included the anaesthetists, the size of the cannula, the site of insertion, and the ease of insertion.

Statistical analysis of the cannula duration was by survival analysis using a K aplan-M eier estimation and multivariate modelling was done using a Cox proportional hazards model with co-variates. The initial variables for the stepwise regression were chosen by a t-test, Chi square, or Wilcoxon as appropriate with a threshold $P$ value of 0.2 .

\section{RESU LTS}

One thousand and eight patients had cannulae inserted for more than 12 hours. Five hundred and three received 0 ptiva $^{\mathrm{TM}}$ cannulae and 505 received Insyte $^{\mathrm{TM}}$ cannulae. These two groups are well matched with respect to age, sex, weight, diabetes, preoperative white cell count and preoperative blood sugar (Table 1). Similarly the two groups were well matched for factors relating to the insertion of the 
TABLE 1

\begin{tabular}{|c|c|c|c|}
\hline & & All Patie & $(n=1008)$ \\
\hline Patient Chara & ristic & Optiva ${ }^{\mathrm{TM}}$ & Insyte ${ }^{\mathrm{TM}}$ \\
\hline A ge (years) & $\begin{array}{r}\text { M ean } \\
\text { SD } \\
M \text { in-M ax }\end{array}$ & $\begin{array}{c}61.5 \\
10.7 \\
18-85\end{array}$ & $\begin{array}{c}61.2 \\
10.9 \\
26-85\end{array}$ \\
\hline Sex & $\begin{array}{r}\text { Male } \\
\text { Female }\end{array}$ & $\begin{array}{l}387(77 \%) \\
116(23 \%)\end{array}$ & $\begin{array}{l}384(76 \%) \\
121(24 \%)\end{array}$ \\
\hline Weight (kg) & $\begin{array}{r}\text { M ean } \\
\text { SD } \\
\text { M in-M ax }\end{array}$ & $\begin{array}{c}77.0 \\
13.8 \\
40-121\end{array}$ & $\begin{array}{c}76.9 \\
12.8 \\
40-121\end{array}$ \\
\hline $\mathrm{H}$ istory of diabetes & $\begin{array}{l}\text { Yes } \\
\text { No }\end{array}$ & $\begin{array}{c}58(12 \%) \\
445(88 \%)\end{array}$ & $\begin{array}{c}80(16 \%) \\
425(84 \%)\end{array}$ \\
\hline $\begin{array}{l}\text { White cell count } \\
\qquad\left(x 10^{3}\right)\end{array}$ & $\begin{array}{r}\text { M ean } \\
\text { SD } \\
\text { M in-M ax }\end{array}$ & $\begin{array}{c}7.4 \\
2.0 \\
1.1-22\end{array}$ & $\begin{array}{c}7.5 \\
2.2 \\
1.1-20.5\end{array}$ \\
\hline $\begin{array}{l}\text { Blood sugar level } \\
\quad(\mathrm{mmol} / \mathrm{l})\end{array}$ & $\begin{array}{r}\text { M ean } \\
S D \\
M \text { in-M ax }\end{array}$ & $\begin{array}{c}6.3 \\
2.7 \\
1.5-19.7\end{array}$ & $\begin{array}{c}6.5 \\
3.0 \\
1.6-23.0\end{array}$ \\
\hline
\end{tabular}

TABLE 2

\begin{tabular}{|c|c|c|c|}
\hline \multirow{2}{*}{\multicolumn{2}{|c|}{ Cannula Characteristics }} & \multicolumn{2}{|c|}{ All Patients $(n=1008)$} \\
\hline & & \multirow{2}{*}{$\begin{array}{c}\text { Optiva }^{\mathrm{TM}} \\
(\mathrm{n}=503) \\
95(19 \%) \\
379(75 \%) \\
29(6 \%)\end{array}$} & \multirow{2}{*}{$\begin{array}{c}\begin{array}{c}\text { Insyte } \\
(n=505)\end{array} \\
100(20 \%) \\
370(73 \%) \\
35(7 \%)\end{array}$} \\
\hline Cannula gauge & $\begin{array}{l}14 \mathrm{ga} \\
16 \mathrm{ga} \\
18 \mathrm{ga}\end{array}$ & & \\
\hline Cannula site (arm) & $\begin{array}{r}\text { Left } \\
\mathrm{R} \text { ight }\end{array}$ & $\begin{array}{c}464(92 \%) \\
39(8 \%)\end{array}$ & $\begin{array}{c}464(92 \%) \\
41(8 \%)\end{array}$ \\
\hline $\begin{array}{l}\text { Cannula site } \\
\text { (position) }\end{array}$ & $\begin{array}{l}\text { er Arm } \\
\text { orearm } \\
\text { Wrist } \\
\text { H and }\end{array}$ & $\begin{array}{r}1(0.2 \%) \\
80(16 \%) \\
143(28 \%) \\
134(27 \%) \\
145(29 \%)\end{array}$ & $\begin{array}{r}1(0.2 \%) \\
74(15 \%) \\
161(32 \%) \\
137(27 \%) \\
132(26 \%)\end{array}$ \\
\hline $\begin{array}{l}\text { D egree of } \\
\text { difficulty }\end{array}$ & $\begin{array}{l}\text { E asy } \\
\text { fficulty } \\
\text { fficulty }\end{array}$ & $\begin{array}{c}440(88 \%) \\
5(1 \%) \\
58(11 \%)\end{array}$ & $\begin{array}{c}434(86 \%) \\
3(1 \%) \\
68(13 \%)\end{array}$ \\
\hline Number of attempts & $\begin{array}{r}1 \\
2 \\
3 \\
\geq 4\end{array}$ & $\begin{array}{c}445(88 \%) \\
47(9 \%) \\
8(2 \%) \\
3(0.6 \%)\end{array}$ & $\begin{array}{c}445(88 \%) \\
51(10 \%) \\
9(2 \%) \\
0(0 \%)\end{array}$ \\
\hline A naesthetist & $\begin{array}{r}1 \\
2 \\
3 \\
4 \\
5 \\
6 \\
7 \\
8 \\
9 \\
10\end{array}$ & $\begin{array}{c}92(18 \%) \\
15(3 \%) \\
123(24 \%) \\
28(6 \%) \\
37(7 \%) \\
3(0.6 \%) \\
78(15 \%) \\
38(8 \%) \\
64(13 \%) \\
27(5 \%)\end{array}$ & $\begin{array}{c}113(22 \%) \\
12(2 \%) \\
101(20 \%) \\
38(8 \%) \\
35(7 \%) \\
3(0.6 \%) \\
67(13 \%) \\
37(7 \%) \\
74(15 \%) \\
23(5 \%)\end{array}$ \\
\hline
\end{tabular}

TABLE 3

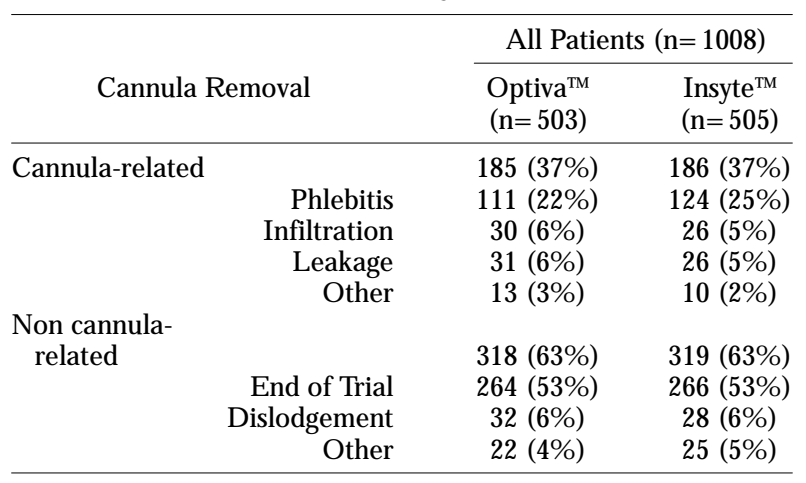

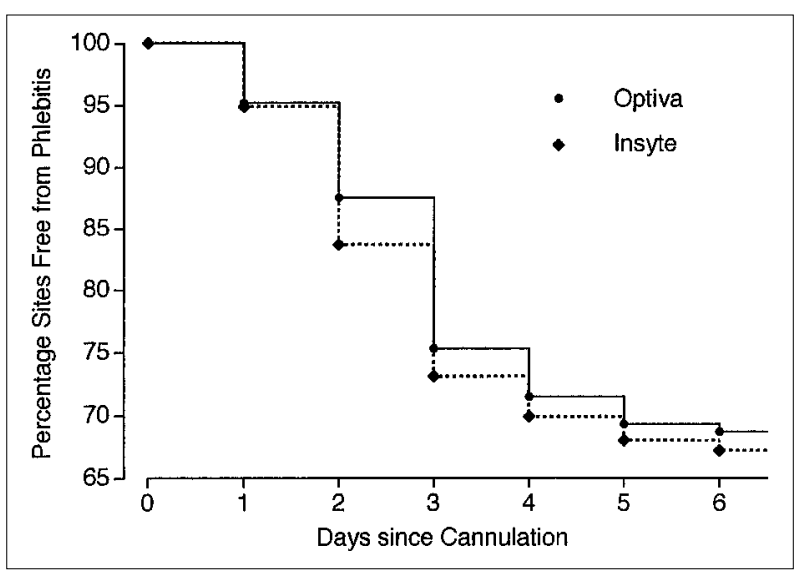

FIGURE 1: The survival of the two types of cannulae for the freedom from phlebitis at the cannula or cannula site. The 0 ptiva $^{\mathrm{TM}}$ survival line is shown as solid dots joined by a continuous line. The survival curves have been extended beyond day 6 for clarity. The Insyte $^{T M}$ is shown as a solid diamond joined by a dashed line. A Ithough there is a better survival of the 0 ptiva $^{T M}$ cannulae, this is not statistically significant.

TABLE 4

\begin{tabular}{|c|c|c|c|c|c|}
\hline Variable & Coeff & $\begin{array}{l}\text { Std } \\
\text { Error }\end{array}$ & $\begin{array}{c}\text { H azards } \\
\text { Ratio }\end{array}$ & $95 \% \mathrm{Cl}$ & $P$ value \\
\hline (Yes:No) & 0.66 & 0.23 & 1.94 & $1.24-3.05$ & 0.0039 \\
\hline $\begin{array}{l}\text { Site of cannula } \\
\text { (A ntecubital:Wrist) } \\
\text { (Forearm:Wrist) } \\
\text { (H and:Wrist) }\end{array}$ & $\begin{array}{c}0.03 \\
0.18 \\
-0.15\end{array}$ & $\begin{array}{l}0.12 \\
0.09 \\
0.10\end{array}$ & $\begin{array}{l}1.03 \\
1.20 \\
0.86\end{array}$ & $\begin{array}{l}0.81-1.30 \\
1.00-1.43 \\
0.70-1.05\end{array}$ & $\begin{array}{l}0.8096 \\
0.0414 \\
0.1357\end{array}$ \\
\hline Nurse assessor & $\begin{array}{l}0.20 \\
0.04\end{array}$ & $\begin{array}{l}0.08 \\
0.08\end{array}$ & $\begin{array}{l}1.22 \\
1.04\end{array}$ & $\begin{array}{l}1.05-1.42 \\
0.89-1.21\end{array}$ & $\begin{array}{l}0.0088 \\
0.6499\end{array}$ \\
\hline
\end{tabular}

A naesthesia and Intensive Care, Vol. 25, N o. 1, February 1997 
cannula (Table 2).

In both groups $47 \%$ of the cannulae were removed before the three days had expired. The commonest reason for removal was phlebitis (0 ptiva ${ }^{T M} 22 \%$ and Insyte $\left.{ }^{\mathrm{TM}} 25 \%\right)$; the difference is not significant ( $P=$ $0.37 \mathrm{Fisher).} \mathrm{A} \mathrm{complete} \mathrm{list} \mathrm{is} \mathrm{given} \mathrm{in} \mathrm{Table} 3$.

With both cannulae there was a progressive increase in phlebitis while the cannula remained in and some continued phlebitis in the three days after removal (Figure 1). However, although the 0 ptiva $^{\text {TM }}$ cannulae had a slightly lower progressive incidence, this difference was not statistically significant. The adjusted survival for $0 \mathrm{ptiva}^{\mathrm{TM}}$ after six days was estimated at $68.7 \%(95 \% \mathrm{Cl} 64.6-72.8)$ and for Insyte ${ }^{\mathrm{TM}}$ was $67.2 \%(95 \% \mathrm{Cl} 63.1-71.3)$.

Only three factors were identified as influencing the incidence of phlebitis with the Cox proportional hazards model. These were: the use of esmolol, the site of the cannulation and the nurse observer identifying phlebitis (Table 4). The hazard ratio expresses the increased risk of the factor being present, e.g. cannulation on the forearm increased the risk of phlebitis 20\% (confidence interval $0-43 \%, P=0.04$ ).

The severity of phlebitis with each type of cannula was also assessed. At each grade the level of phlebitis was similar with both cannulae $(P=0.41 \mathrm{Chi}$ square, Figure 2). In addition, the type of reaction was also similar (Figure 3). N one of these reaction differences between cannulae was statistically significant (all categories $\mathrm{P}>0.02$ ).

When the cannulae were removed, the shaft and tip of every cannula were examined. Evidence of damage was noted in $80 \mathrm{Optiva}^{\mathrm{TM}}$ cannulae and 120 Insyte ${ }^{T M}$ cannulae (Figure 4). Shaft kinking occurred to both types in about equal frequency $(6.1 \%$ and $8.2 \%$ respectively). However, the incidence of tip damage or distortion with Insyte ${ }^{\mathrm{TM}}$ was significantly greater than with 0 ptiva $^{T M}(P=0.0001 \mathrm{~F}$ isher $)$.

\section{DISCU SSION}

The two cannulae groups are very well matched for the characteristics examined and gives grounds for confidence in the randomization. There was no statistically significant difference in phlebitis between the two cannulae three days after insertion and in the subsequent three days of observation. The incidence of phlebitis over the six days was 31\% with the O ptiva ${ }^{\mathrm{TM}}$ cannula and $33 \%$ with the Insyte ${ }^{\mathrm{TM}}$. With 1008 patients and assuming an $\alpha=0.20$, this trial has an estimated power of $87 \%$ to detect a real difference of $5 \%$. A s the difference in phlebitis seen was $2 \%$ it is unlikely that a clinically significant difference in these two cannulae has been missed.

A Ithough $22 \%$ of the Optiva ${ }^{\mathrm{TM}}$ and $25 \%$ of the Insyte ${ }^{T M}$ were removed because phlebitis was identified, a further $15 \%$ of 0 ptiva $^{\text {TM }}$ and $12 \%$ of Insyte ${ }^{T M}$ cannulae were removed early for other reasons. The survival incidence at day 3 adjusted for the nonphlebitis removals is $75.3 \%$ ( $95 \%$ confidence intervals $71.5-79.1)$ for 0 ptiva $^{\text {TM }}$ and $73.1 \%(95 \% \mathrm{Cl} 69.2-$ 77.0) for Insyte ${ }^{\mathrm{TM}}$ respectively. At day 6 the survival

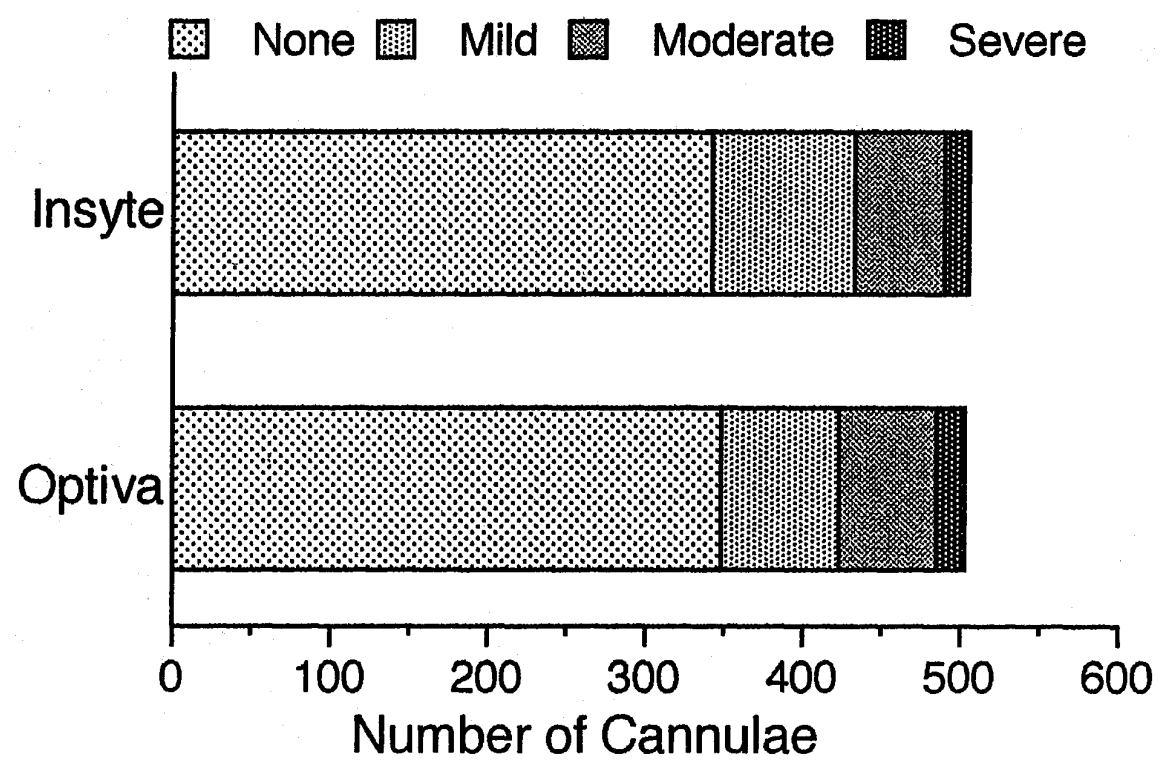

FIGURE 2: Comparison of the incidence and degree of phlebitis found in the $0 \mathrm{ptiva}^{\mathrm{TM}}$ and Insyte ${ }^{\mathrm{TM}}$ cannulae. M ost cannulae showed no phlebitis but in those which did the grades of severity were equally distributed between the two types. 


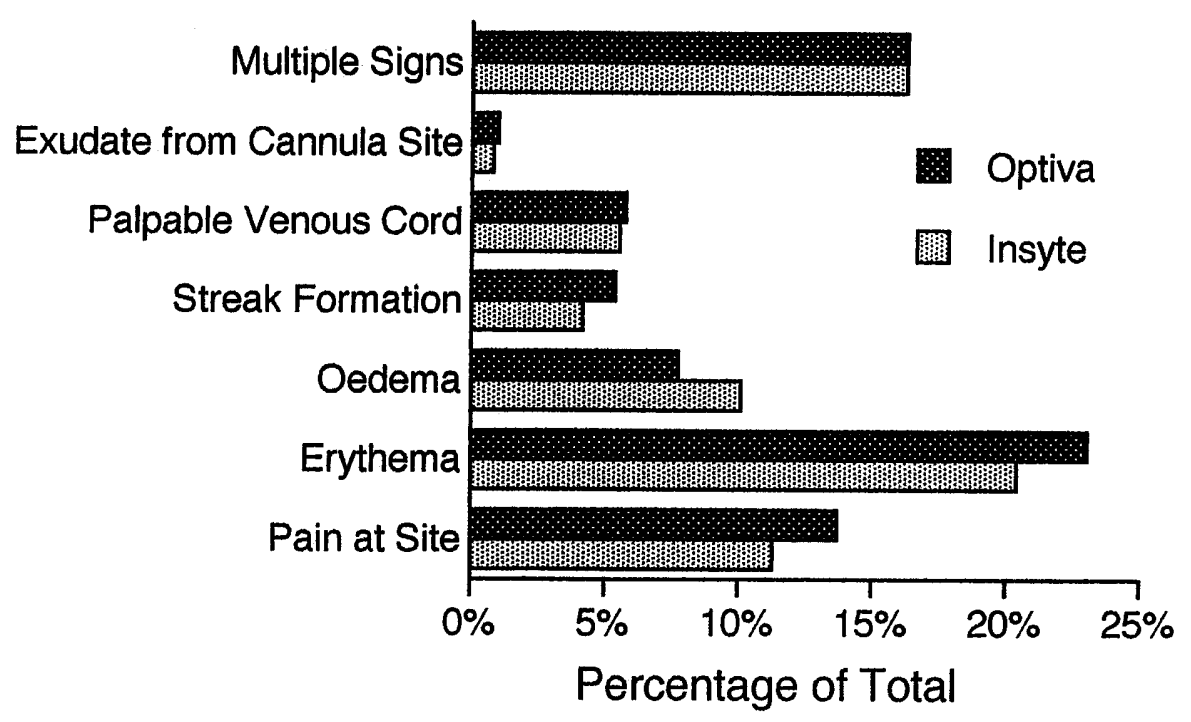

FIGURE 3: Comparison of the type and frequency of phlebitis found in the O $\mathrm{ptiva}^{\mathrm{TM}}$ and Insyte ${ }^{\mathrm{TM}}$ cannulae. M ost cannulae showed no phlebitis but in those which did the patterns of the phlebitic response were equally distributed between the two types.

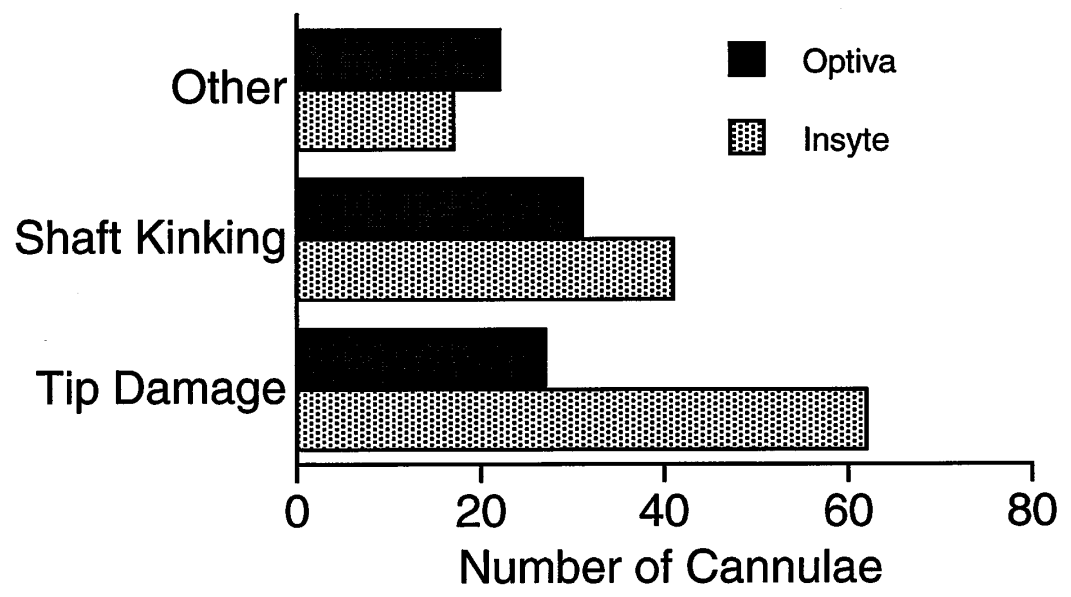

FIGURE 4: Comparison of the type of cannula damage found with the $0 \mathrm{ptiva}^{\mathrm{TM}}$ and Insyte ${ }^{\mathrm{TM}}$ cannulae. Tip damage was more frequent with the Insyte ${ }^{T M}(P=0.0001)$. H owever, this did not appear to affect the incidence of clinical phlebitis.

(i.e. non-phlebitis rate) is $68.7 \%$ ( $95 \%$ confidence intervals 64.6-72.8) for O ptiva ${ }^{\mathrm{TM}}$ and $67.2 \%(95 \% \mathrm{Cl}$ 63.1-71.3) for Insyte ${ }^{\mathrm{Tm}}$. This shows that in both groups there was about $10 \%$ additional phlebitis over the three days after removal. The first day post-removal however, has about $50 \%$ of the additional phlebitis and if the second day is included this will cover over $80 \%$ of the delayed phlebitis. Thus this pattern is faster than an exponential decay and it can be reasonably extrapolated that over $90 \%$ of the addi- 
tional change will be observed within the three days.

The Cox's proportional hazard model to identify the major factors in phlebitis in this study found three parameters of interest. The use of esmolol is identified as the most significant factor. This must remain in doubt as the number of patients receiving esmolol was very small. However esmolol is well known to provoke histamine release so that a phlebitic enhancement may be expected. The site of cannulation is of significance as the use of the mid forearm veins is common. Possibly in the cardiac scenario when patients are cold and vasoconstricted these veins are experiencing an unusually low flow as they tend to be superficial.

It appears that in spite of differences in appearance and needle profile, both the 0 ptiva $^{\text {TM }}$ and the Insyte ${ }^{T M}$ cannulae have a similar risk of phlebitis in clinical use and similar survival expectations.

\section{ACKNOWLEDGEMENT}

The financial support of Johnson \& Johnson Research Pty Limited is gratefully acknowledged. $\mathrm{H}$ elp with data preparation by M rs J ulie J ones and $\mathrm{Dr}$
Peter Spencer and assistance with statistical analysis by $\mathrm{M} \mathrm{r}$ Stephen $\mathrm{H}$ al pin of $\mathrm{D}$ atapharm A ustralia is also acknowledged with thanks.

\section{REFERENCES}

1. $M$ aki $D, R$ inger $M$. R isk factors for infusion-related phlebitis with small peripheral venous catheters. A nn Intern M ed 1991; 114:845-854.

2. Larsson N, Stenberg K, Linder L-E, Curelaru L. Cannula thrombophlebitis: a study in volunteers comparing polytetrafluorethylene, polyurethane, and polyamide-ether-elastomer cannulae. A cta A naesthesiol Scand 1989; 33:223-231.

3. M cK ee J M, Shell JA, Warren TA, Campbell V P. Complications of intravenous therapy: a randomized prospective studyVialon vs. Teflon. J Intravenous N ursing 1989; 12:288-295.

4. Gaukroger PB, Roberts JG, M anners TA. Infusion Thrombophlebitis: a prospective comparison of $645 \mathrm{~V}^{2}$ alon $^{\mathrm{TM}}$ and Teflon ${ }^{\mathrm{TM}}$ cannulae in anaesthetic and postoperative use. A naesth Intensive Care 1988; 16:265-271.

5. Payne-J ames J J., Rana SK, Rogers J, M cSwiggan D, Bray MJ, Silk D BA. D evelopment of thrombophlebitis in peripheral veins with Vialon and PTFE-Teflon cannulas: a double-blind randomised controlled trial. Ann R Coll Surg Engl 1991; 73:322325.

6. Tebbs SE, Sawyer A, Elliott TSJ. Influence of surface morphology on in vitro bacterial adherence to central venouscatheters. Br J A naesth 1994; 72:587-591. 